\title{
Cold Wave Climate Characteristics and Risk Zoning in Jilin Province
}

\author{
Shiqi Xu' ${ }^{1,2}$, Xueyan Yang1, Rui Sun ${ }^{3}$, Shuai Fư ${ }^{4}$, Honghai Liang1, Linan Chen ${ }^{5}$ \\ ${ }^{1}$ Climate Center of Jilin Province, Changchun, China \\ ${ }^{2}$ Jilin Provincial Key Laboratory of Changbai Mountain Meteorology \& Climate Change, Changchun, China \\ ${ }^{3}$ Climate Center of Sichuan Province, Chengdu, China \\ ${ }^{4}$ Institute of Space Weather of NUIST, Nanjing, China \\ ${ }^{5}$ Liaoyuan City Meteorological Station, Liaoyuan, China \\ Email: xushiqi91@163.com
}

How to cite this paper: Xu, S.Q., Yang, X.Y., Sun, R., Fu, S., Liang, H.H. and Chen, L.N. (2018) Cold Wave Climate Characteristics and Risk Zoning in Jilin Province. Journal of Geoscience and Environment Protection, 6, 38-51.

https://doi.org/10.4236/gep.2018.68004

Received: June 28, 2018

Accepted: August 10, 2018

Published: August 13, 2018

Copyright $\odot 2018$ by authors and Scientific Research Publishing Inc. This work is licensed under the Creative Commons Attribution International License (CC BY 4.0).

http://creativecommons.org/licenses/by/4.0/

(c) (i) Open Access

\begin{abstract}
Using the meteorological data of 50 stations in Jilin Province from 1961 to 2016, the demographic and economic data, and geographical information of all counties and cities aims to conduct the risk zoning of cold wave disasters in Jilin Province. The results show that, since 1961, the average number of cold wave occurrences per year in Jilin Province is 8.3 days, of which the highest number of occurrences occurred in February, followed by December and January, and the spring cold wave occurred mostly in March. From the map of cold-sea disaster risk zoning in Jilin Province, due to factors such as topography and land use distribution, the west and east of Jilin Province have a certain resilience to the disasters caused by cold waves, and the risk of disasters is low. The distribution of agricultural facilities and large areas of farmland in the central region are extremely sensitive to cold wave disasters and have a high risk of disasters. Areas with high risk of cold wave are mainly concentrated in Siping City, Changchun City, Liaoyuan City, Jilin City, northern Tonghua City and most of Baishan City. Areas with low cold wave risk are mainly concentrated in most of Baicheng City, most of Songyuan City and Yanbian Prefecture. And other places are moderately risky areas of cold waves.
\end{abstract}

\section{Keywords}

Jilin Province, Cold Wave, Climate Characteristics, Risk Zoning, GIS

\section{Introduction}

Meteorological risk disasters usually refer to the occurrence of meteorological 
disasters and their possible impacts and hazards on the natural environment, society and economy [1]. The types of meteorological disasters are numerous, high in frequency, wide in range, long in duration, and endangered. They are the largest disasters causing people's property losses in natural disasters [2] [3] [4] [5] [6]. Jilin Province is located in the mid-latitudes of the northern hemisphere, the eastern part of the Eurasian continent, the northern temperate zone of China, close to the sub-frigid zone, and belongs to temperate continental monsoon climate. Cold wave mainly occurs in the late autumn to the beginning of next spring. It is one of the major meteorological disasters in Jilin Province and occurs every year. Severe cooling and windy weather are the main features of the cold wave, accompanied by rain, snow, and frost, which have a great impact on transportation, industry, agriculture, and human health, causing huge losses to the national economy. The occurrence of spring cold weather in spring will cause frostbite in corn and rice, which will lead to a decline in yield. The occurrence of cold weather in autumn can cause frost damage to late autumn crops, resulting in reduced yields or outbreaks. In winter, it may cause freezing of trees and crops, frost damage to people and livestock, floods, construction. At the same time, strong winds, rain, and snow from cold waves often cause low visibility, icing and snow on the surface, and threaten traffic safety; freezing rain caused by cold waves can cause transmission lines to be interrupted. The strong cooling caused by the cold wave can easily lead to colds, bronchitis, and cardiovascular diseases [7] [8] [9].

Disaster risk assessment is the quantitative analysis and assessment of the possibility of different intensity disasters in a certain risk area and its possible consequences [10]. Through risk identification, risk assessment and risk evaluation, disaster risk management is effectively controlled and the consequences of risk losses are properly handled to reduce disaster losses as much as possible. Therefore, it is necessary to establish a disaster risk assessment system and work out disaster risk thematic maps. Liu et al. [11] studied Jilin Province's agricultural meteorological drought disaster risk zoning, and pointed out that meteorological drought sensitive areas are mainly distributed in Baicheng City, Songyuan City, Changchun City and Siping City in the central and western regions of Jilin Province. Wang et al. [12] carried out risk zoning for late-warning chilling damage of rice in Jilin Province, and pointed out that the risk of low-temperature chilling injury is relatively low in most of the western Jilin Province, most of Siping and the south of Tonghua. In eastern Yanbian and Baishan cities, there is a high risk of low-temperature chilling. At present, there are many studies on the zoning of agricultural disasters in Northeast China [13] [14] [15] [16] [17], but there are still some limitations in the study of meteorological disaster risk zoning [18] [19]. This article defines that the 24-hour minimum temperature falls by more than $8^{\circ} \mathrm{C}$, and that the minimum daily temperature is below $2^{\circ} \mathrm{C}$ is a cold-wave process. Based on GIS technology, the meteorological data of 50 meteorological stations in Jilin Province from 1961 to 2016, comprehensive social data and nat- 
ural environment data are used to comprehensively analyze the risk of cold wave disasters in Jilin province from the hazards of hazard factors and vulnerability of disaster-bearing bodies (hazard inducing environment, disaster-affected body, and disaster prevention capability). Through the selection of suitable cold wave disaster assessment factors, the spatial distribution of cold wave disaster risk in Jilin Province was analyzed and constructed using the weighted comprehensive evaluation method to make up for the gap in the current risk classification of meteorological disasters in Jilin Province to rationalize the layout of crops, scientific planning, improve the ability to respond to cold wave disasters, ensure agricultural production, reduce the loss of the people and provide a certain scientific basis.

\section{Source of Information}

The data in this article mainly includes the daily minimum temperature data of 50 meteorological stations in Jilin Province from 1961 to 2016, the socioeconomic data of Jilin Province in 2016 (including the total population, gross value of production, total agricultural output value, etc.) and geographic information data (Including the type of land use in the province, water system of 1:50,000, etc.).

\section{Cold Wave Climate Characteristics}

According to the annual meteorological data of 50 meteorological stations in Jilin Province, frequency statistics analysis method was used to obtain the frequency of cold wave (days) and intensity (yearly maximum cooling rate) of each site in Jilin Province since 1961. The average number of days of cold wave occurring in Jilin Province is 8.3 days per year. The months with the highest number of cold wave days were mainly concentrated in February, followed by January and December. The least cold wave occurred in June, July and August. the spring cold wave occurred mostly in March (Figure 1). Figure 2 shows the inter-annual variation of cold wave days in Jilin Province. In 1965, the average number of days of cold wave weather in Jilin Province was the highest (12.8 days). In 1995, the average number of days of cold wave weather in Jilin Province was the lowest (4.4 days). Before 1980, the average number of days of cold wave weather in Jilin Province was 8.8 days. After 1980, the average number of days of cold wave weather in Jilin Province was 8.0 days. In the past 10 years, the number of cold wave days in Jilin Province has shown a tendency of increasing fluctuations. On average, cold waves have occurred 8.1 days per year, and there have been 10.9 days of cold waves in 2014. This is the year with the highest number of cold wave days in the past 10 years.

Spatial interpolation of the frequency and intensity of cold wave in Jilin Province (Figure 3, Figure 4). The cold wave disasters mainly occurred in the southeast of Jilin Province, and the spatial distribution gradually decreased from southeast to northwest. Among them, most of Tonghua City, most of Jilin City 


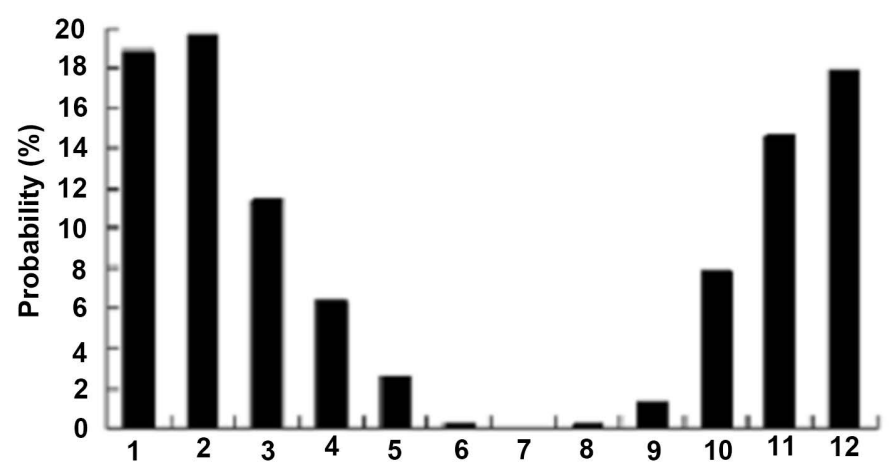

Figure 1. Distribution of cold wave in each month in Jilin Province.

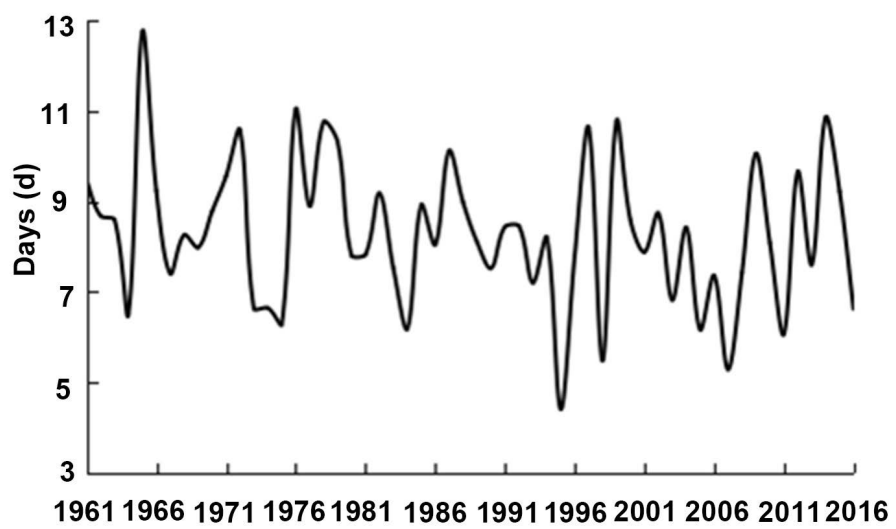

Figure 2. Inter-annual variation of cold wave days in Jilin Province.

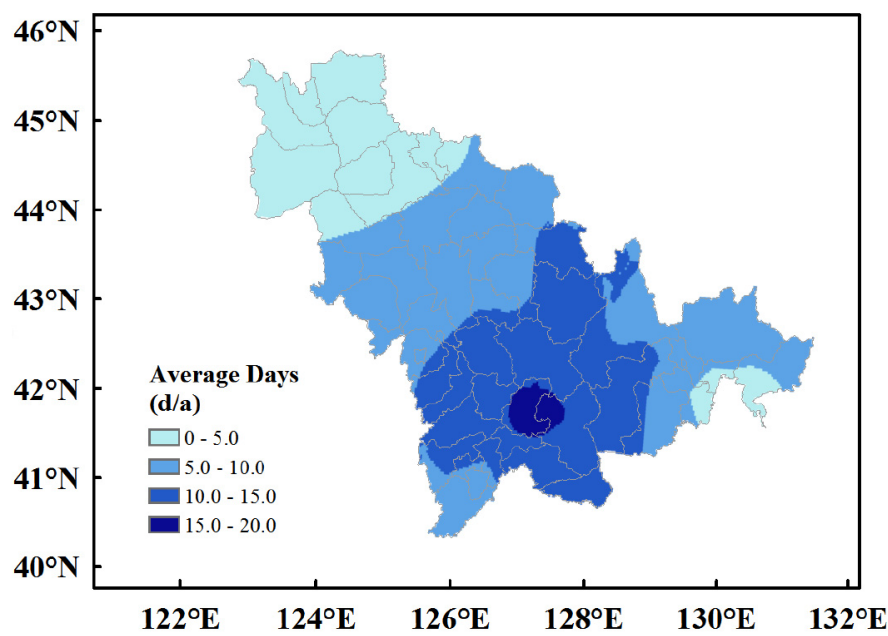

Figure 3. Frequency of cold wave in Jilin Province (d/a).

and Baishan City, and Dongfeng, Antu, and Songjiang were cold wave-prone regions in Jilin Province. The average annual occurrence of cold wave disasters is 10.3 - 23.5 days; most of Baicheng City, Songyuan City, and Yanji, Longjing, and Hunchun are cold springs in Jilin Province, with an average of 3.0 - 4.9 days of cold wave occurring each year; the average annual occurrence of cold waves is 


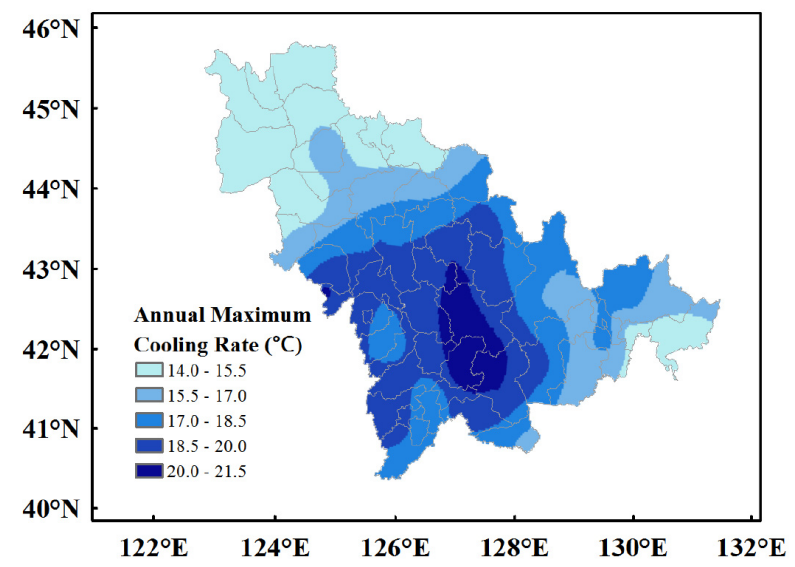

Figure 4. Annual maximum intensity of cold wave in Jilin Province $\left({ }^{\circ} \mathrm{C}\right)$.

5.0 - 9.3 days in other regions. The largest annual temperature drop in Jilin Province occurred in most of Siping City, southern Changchun City, most of Jilin City, most of Tonghua City and most of Baishan City, which was $18.6^{\circ} \mathrm{C}$ $-21.5^{\circ} \mathrm{C}$; most of Baicheng City and Songyuan City were The annual cooling rate of ours, Helong and Hunchun is the smallest, ranging from $13.8^{\circ} \mathrm{C}$ to $15.1^{\circ} \mathrm{C}$; the maximum cooling rate in other places is $15.6^{\circ} \mathrm{C}$ to $18.3^{\circ} \mathrm{C}$. The special terrain feature of Jilin Province is the main reason for the uneven spatial distribution of cold waves [20]. The cold wave weather in the southeast of Jilin Province was mainly due to the topography of Changbai Mountain. The cold wave in the central region was more than the western region due to the transport of warm and humid air in the southwest.

\section{Cold Wave Disaster Risk Assessment and Zoning}

\subsection{Assessment Model}

The risk of hazard factors and vulnerability of hazard bearing bodies are two major components of the meteorological disaster risk system [10]. This article first evaluates the risk of cold wave and the vulnerability of the disaster bearing body, and evaluates the risk of cold wave disasters. Cold wave disaster risk assessment model adopts formula [10]:

$$
R=H \times V
$$

Among them, $R$ is the disaster risk, $H$ is the hazard factor hazard, and $V$ is the disaster vulnerability.

Through concrete analysis, a cold storm meteorological disaster risk assessment index system was established, and the corresponding weights of each index were determined using the analytic hierarchy process [21] [22] (Figure 5). Details as follows:

1) Establish a risk assessment index system. According to the cold wave risk assessment requirements, the evaluation index system is specifically divided into target layer, criterion layer, and index layer. 


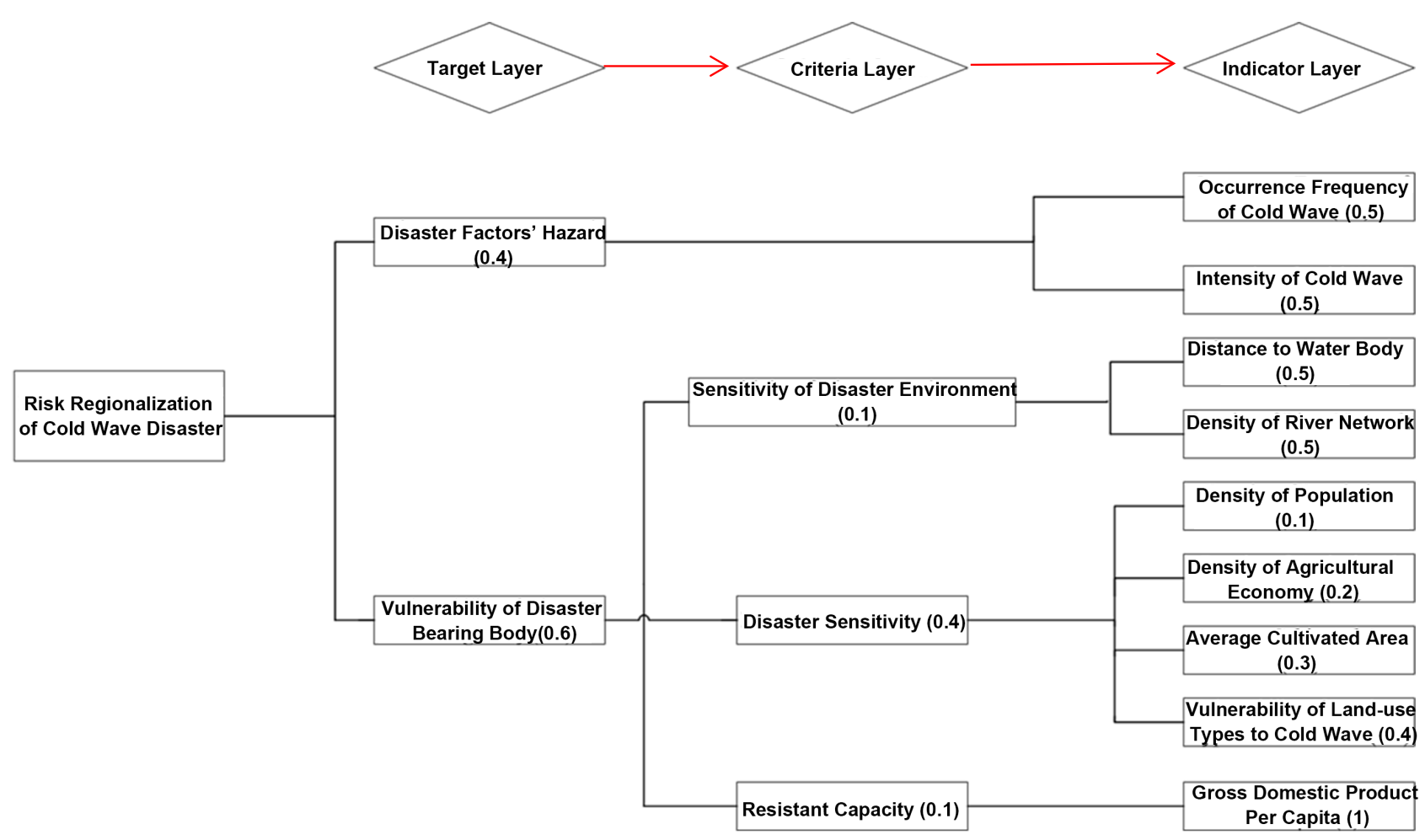

Figure 5. Risk assessment system and weight of cold wave disaster in Jilin Province.

The target level includes the hazard of hazard and the vulnerability of the carrier. The frequency and intensity of the hazard factor activity are the main factors that determine the risk of hazards [23]. Therefore, the risk of disasters in this paper mainly considers the frequency and intensity of the occurrence of cold wave weather at various stations in Jilin Province. The vulnerability of disaster-affected body is composed of three parts: 1) When the climate background is the same, the geographical and geomorphological conditions of the quake-hit environment (the natural environment that bred the cold wave disaster) can largely influence the occurrence of the cold wave disaster-causing factors and secondary disasters. Because the underlying surface of water bodies and wetlands has a certain degree of insulation effect, the damage caused by cold wave disasters can be effectively reduced. Therefore, when considering the environmental sensitivity of gestational disasters, the distance and distance between the water body and the river network density should be considered. 2) Sensitivity to disasters refers to the response of the disaster-affected body to the disaster, which is determined by the land use type, population, and property of the study area. Jilin Province is a large agricultural province. Compared with animal husbandry and forestry, cold waves have a greater impact on agriculture. Therefore, the vulnerability of cold-swamps, agricultural economic density, average cultivated land area, and population density were selected as the main factors of vulnerability. 3) Disaster prevention and mitigation capabilities include resources for disaster reduction input, emergency management, and other aspects, and 
generally refer to the degree and capability of the affected area to resist and restore meteorological disasters. The greater GDP per capita in the region indicates that the higher the level of economic development in the region, the faster the resilience after being destroyed by the cold wave disaster and the stronger the ability to resist disasters. Therefore, choosing per capita GDP as the main factor for disaster prevention and reduction capabilities.

2) The analytic hierarchy process determines the weights. Firstly, establish the comparison matrix of the two comparisons, and use the 1 - 9 scale method to characterize the importance of each item in the matrix. Calculate the maximum eigenvalue of the judgment matrix and feature vector of the judgment matrix (and normalize the feature vectors). The relative weight is the normalized feature vector value. Finally, the deviation consistency test is performed on the judgment matrix, and the degree of deviation from the complete consistency of the judgment matrix is determined by the size of the consistency index.

3) According to the risk assessment model (1), the weighted comprehensive evaluation method [24] is used to synthesize various indicators, and the risk of hazard factors and the vulnerability of the carrier are evaluated separately, and a quantification factor is used for concentration. The formula is:

$$
V=\sum_{i=1}^{n} W_{i} \cdot D_{i}
$$

In the formula, $n$ is the number of evaluation sub-factors; $D_{i}$ is the normalized value of the sub-factor $i, W_{i}$ is the weight of the sub-factor $i$, and $V$ is the value of the evaluation factor. When the various factors are quantified and concentrated, the various data are first normalized to eliminate dimensional differences between different factors [25]. The formula is:

$$
D_{i j}=0.5+0.5 \times \frac{A_{i j}-\min _{i}}{\max _{i}-\min _{i}}
$$

In the formula, $\min _{i}$ and $\max _{i}$ are the minimum value and the maximum value of the $i$-th factor value, $A_{i j}$ is the $i$-th factor value of the $j$ region, and $D_{i j}$ is the normalized value of the $i$-th factor of the $j$ region.

\subsection{Hazard Risk}

The frequency and intensity of occurrence of cold wave weather at each station calculated in Section 2 (the extent of temperature decrease) was calculated using the Kriging interpolation method to map the cold wave hazard distribution in Jilin Province (Figure 6). Generally, the higher the frequency and intensity of the hazard-causing activities, the more serious the damage caused by the disaster and the greater the risk of disasters. The natural breakpoint grading method is used to classify the cold wave hazard distribution into 5 levels. It can be seen that the high-risk areas of cold wave disasters in Jilin Province are located in most of Siping City, most of Jilin City, most of Liaoyuan City, and most of Tonghua City. Most of Baishan City and Yanji and Wangqing; most of the cities of Baicheng, Songyuan, and Yanbian are low-risk areas of cold wave disasters. 


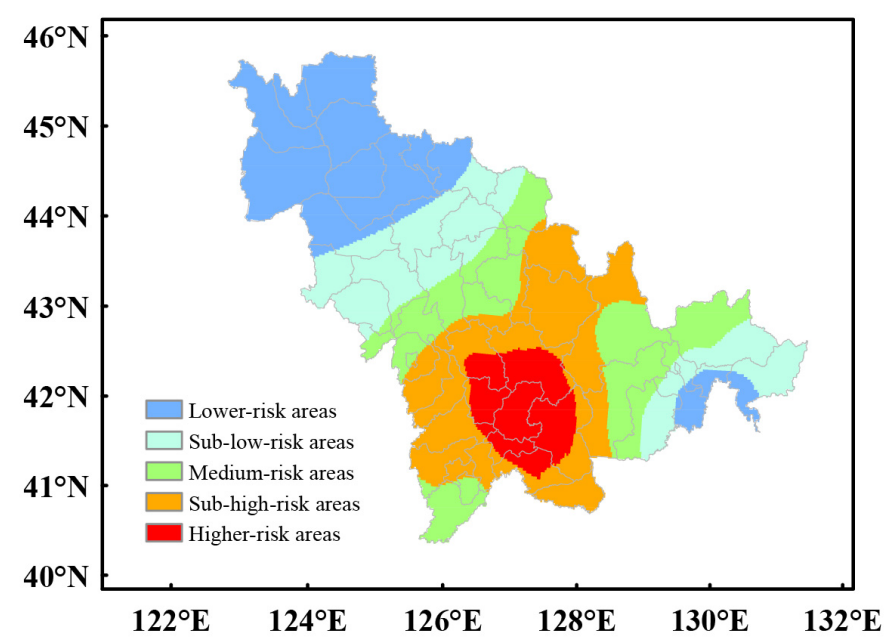

Figure 6. Distribution of cold wave dangerous grade in Jilin Province.

\subsection{Carrier Vulnerability}

\subsubsection{Hazard Inducing Environment}

Using GIS buffer function can realize the influence of water distance and density of river network on susceptibility to gestational environment [26]. In the 1:500 000 water density map, lakes and reservoirs are divided into first-level buffers and second-level buffers according to the area of waters and rivers according to first-level rivers and second-level rivers, according to the secondary waters and secondary rivers. The buffer assignment is the largest, and the principle of maximum assignment in the first-level buffer of a large-scale water body and a river is given, and an appropriate influence factor value between 0 and 1 is given (Table 1, Table 2). When calculating the river network density (the total length of the river within a unit area), the river network density at the central grid point is the total river length within the radius.

Divide the distance between the water body and the density of the river network. Interpolate the results into a $1000 \mathrm{~m}$ resolution grid map (Figure 7). Using the weight coefficient determined in Figure 5 and formulation (2) to calculate the hazard inducing environmental sensitivity index (Figure 8). Generally, the distance from large reservoirs, rivers, lakes, etc., where the river network is denser, the less sensitive the typhoon environment, the lower the risk of cold wave disasters. The farther away from large reservoirs, rivers, and lakes are, the more sparse the river network is, the more sensitive the typhoon-induced environment is, and the higher the risk of cold-wave disasters. It can be seen that the places with large environmental susceptibility indices for cold-water hazards in Jilin Province are mainly concentrated in northern Songyuan and central Jilin.

\subsubsection{Disaster Sensitivity}

The vulnerability of the type of land use to the cold wave disaster, agricultural economic density, average cultivated land area and population density are the main factors of vulnerability. When processing, the Kriging Interpolation of 
Table 1. Divisions of lakes and reservoirs buffer grades and widths.

\begin{tabular}{ccc}
\hline \multirow{2}{*}{$\begin{array}{c}\text { Water Area } \\
\times 10^{4} \mathrm{~km}^{2}\end{array}$} & Buffer Width/km \\
\cline { 2 - 3 }$>20$ & 4 & Level 2 buffer \\
\hline $10-20$ & 3 & 8 \\
$1-10$ & 2 & 6 \\
$0.1-1$ & 0.5 & 4 \\
\hline
\end{tabular}

Table 2. Divisions of river buffer grades and widths.

\begin{tabular}{cccc}
\hline \multicolumn{3}{c}{ Buffer Width/km } \\
\hline \multicolumn{2}{c}{ Primary River } & \multicolumn{2}{c}{ Secondary River } \\
\hline Level 1 buffer & Level 2 buffer & Level 1 buffer & Level 2 buffer \\
8 & 12 & 6 & 10 \\
\hline
\end{tabular}
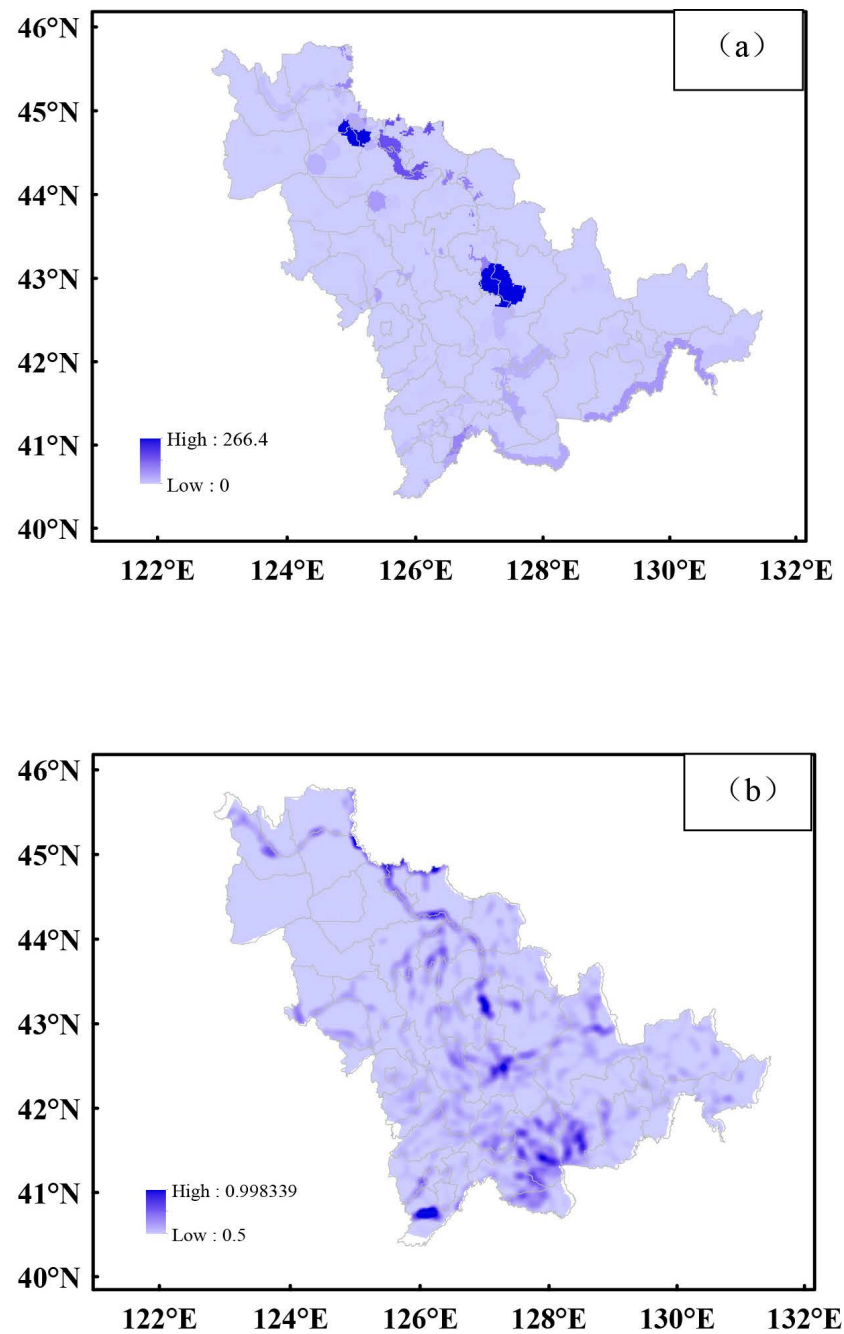

Figure 7. Distribution of water impact index of cold wave in Jilin Province. (a) Distance to water body; (b) River network density. 


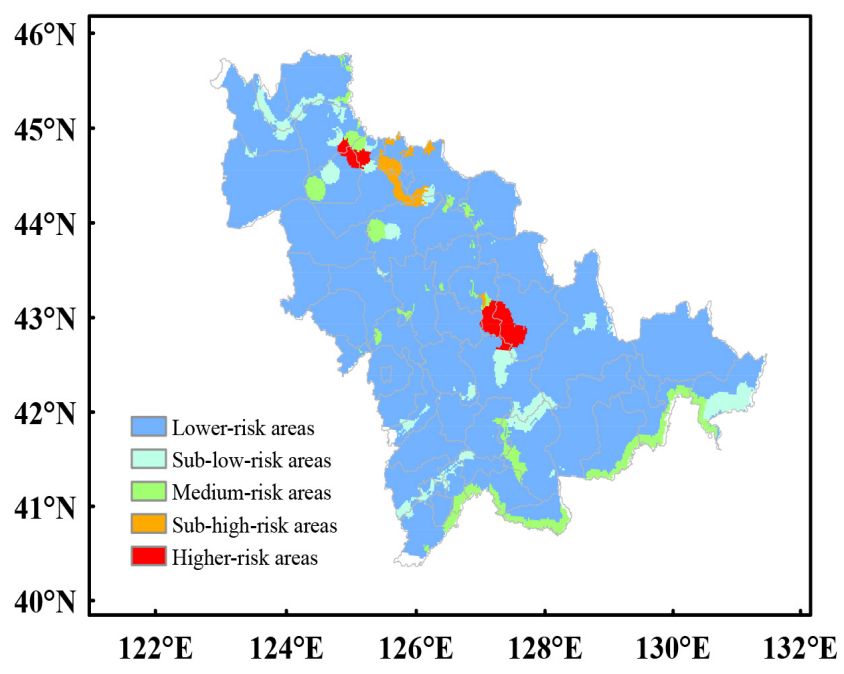

Figure 8. Distribution of cold wave environmental sensitivity in Jilin Province.

population density, agricultural economic density, and average arable land area in counties will be separately used as the spatial grid distribution at a resolution of $1000 \mathrm{~m}$. When considering the type of land use for the cold-water vulnerability index, various land-use types in Jilin Province were reclassified into six categories( land $\mathrm{A}$, forest land $\mathrm{B}$, grassland $\mathrm{C}$, water areas $\mathrm{D}$, urban and rural industrial and resident land E, unused land F) according to the sensitivity of various types of land-use to cold-wave and land resource classification systems. And re-sampled to the same $1000 \mathrm{~m}$ resolution land use grid. Then use the area weight interpolation method to calculate the vulnerability index of the disaster-affected body of each grid to the cold wave disaster, and then obtain the distribution data of the vulnerability of Jilin Province [27]. The specific assumption is that there are multiple land use types $A, B$, and $C$ in each grid (this article is divided into six types). The corresponding areas for each type are $S_{A}, S_{B}$, $S_{C}$, and the corresponding vulnerability degree of each type are $K_{A}, K_{B}, K_{C}$, the vulnerability index $(K)$ for fine-tuning land use types in this cell grid for cold waves is:

$$
K=K_{A} S_{A}+K_{B} S_{B}+K_{C} S_{C}
$$

Using the weight coefficients determined in Figure 5 and Equation (2), the distribution of the sensitivity index of the cold-swept disaster situation is calculated (Figure 9). In general, the higher the sensitivity of the disaster, the greater the damage that may be incurred and the higher the risk of disaster. The coldness disaster sensitivity index distribution is divided into 5 levels. It can be seen that the cold wave disaster sensitive areas in Jilin Province are mainly concentrated in most of Songyuan City, Siping City, Changchun City, and Baicheng District; most of Jilin City and most of Tonghua City, Baishan City and Yanbian Prefecture are low-sensitivity areas of cold wave disasters. 


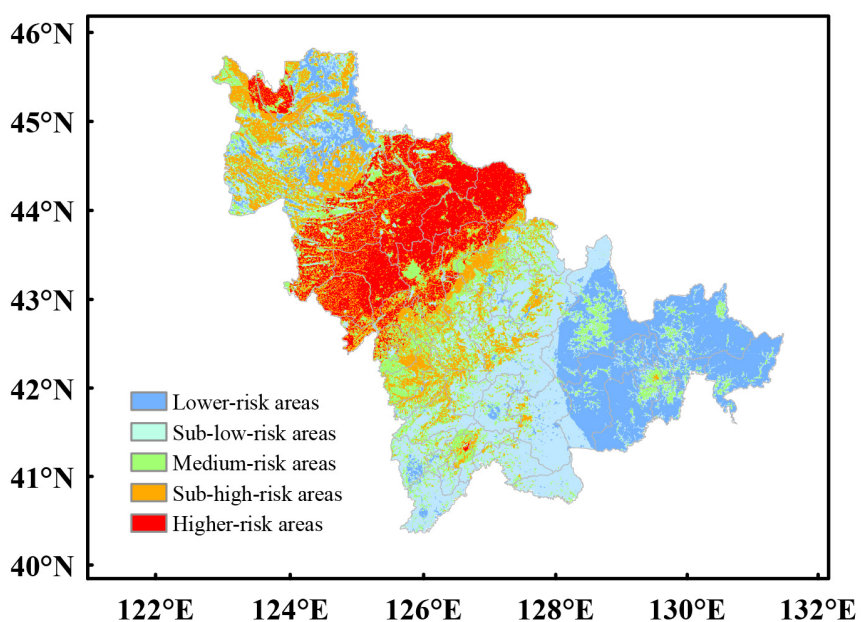

Figure 9. Distribution of cold wave disaster sensitivity in Jilin Province.

\subsubsection{Emergency Response \& Recovery Capability}

The per capita GDP of counties and cities with good statistics was used as a capacity factor for disaster prevention and mitigation. The higher the GDP, the stronger the cold wave disaster prevention and mitigation ability. The interpolation was a $1000 \mathrm{~m}$ resolution spatial grid and was divided into five levels (Figure 10). In general, the stronger the ability to prevent and mitigate natural disasters, the smaller the potential loss, and the lower the level of disaster risk. The areas with low resilience are mainly located in most of Songyuan City, Changchun City Station, Liaoyuan, Liuhe, Jilin, Huadian, Tonghua County, Linjiang, Yanji, and Hunchun, while most of Baicheng City, most of Siping City, and most of Jilin City Most of the northern part of Tonghua City and Yanbian Prefecture have strong resilience.

\subsection{Risk Division}

Based on the above analysis of the four aspects of the risk of cold wave, sensitivity to environmental susceptibility to catastrophes, sensitivity to cold wave disasters, and ability to prevent and mitigate disasters, the hazard index $\left(I_{1}\right)$, susceptibility to environmental susceptibility index $\left(I_{2}\right)$, and sensitivity Sex Index $\left(I_{3}\right)$ and Disaster Prevention and Mitigation Capability Index $\left(I_{4}\right)$, according to the weight coefficient in the indicator system of Figure 5 and Equation (2), calculate the cold wave disaster risk index for each grid point $(I)$ :

$$
I=0.4 I_{1}+0.1 I_{2}+0.4 I_{3}+0.1\left(1-I_{4}\right)
$$

According to the GIS natural breakpoint grading method, the cold wave disaster risk index of Jilin Province is divided into five levels, and the GIS spatial analysis and production function is used to draw the cold wave disaster risk zoning map of Jilin Province (Figure 11).

Because of the influence of topography and land use distribution, the western and eastern parts of Jilin Province suffer from low risk of cold wave disasters; while in the central region there are a large number of facility agriculture and 


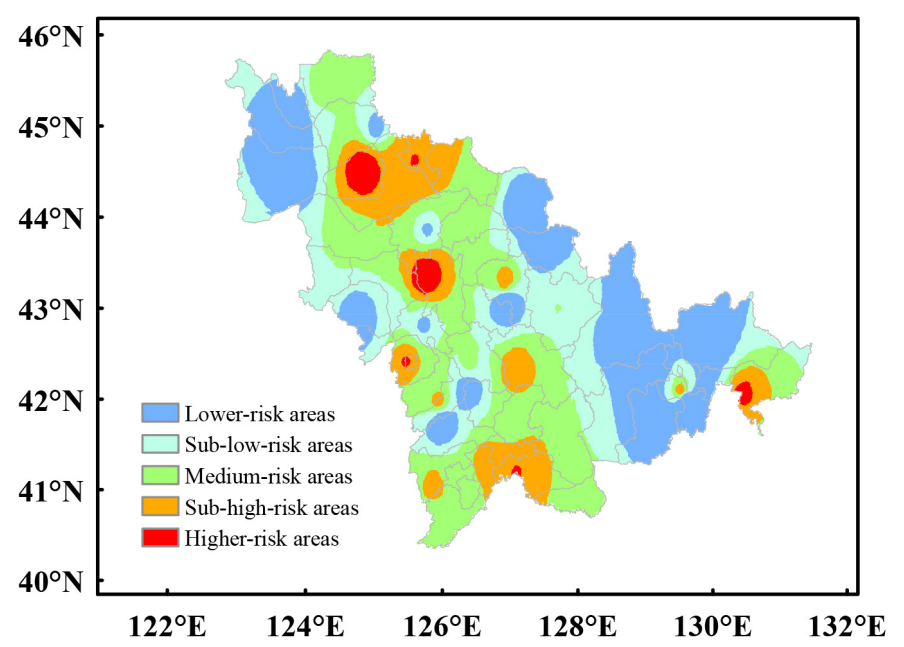

Figure 10. Distribution of cold wave prevention and mitigation capacity in Jilin.

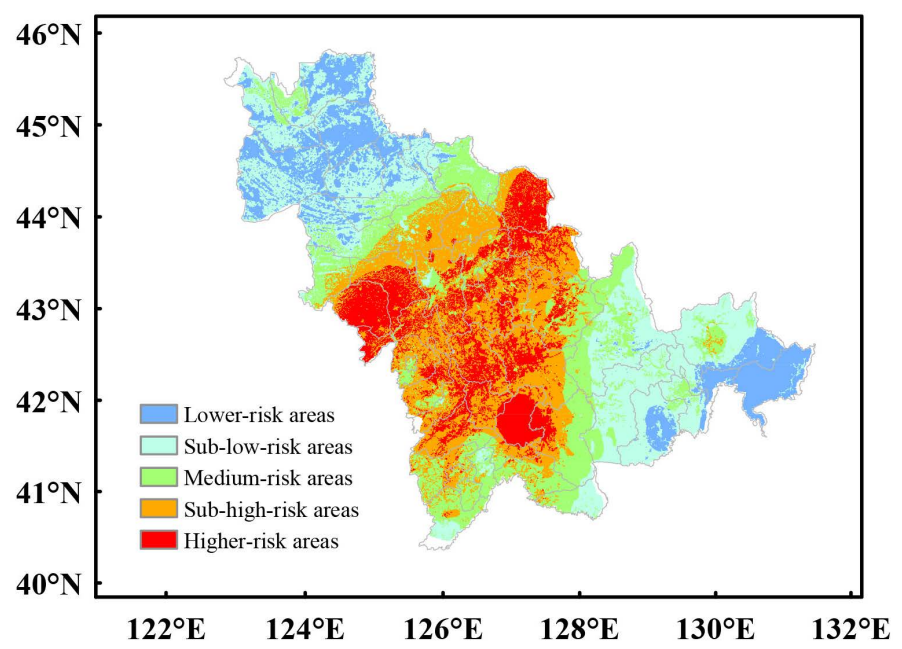

Figure 11. Integrated risk regionalization of cold wave disaster in Jilin Province.

large-area farmland, which are most sensitive to cold waves and have the highest risk of disasters. Areas with high risk of cold wave are mainly concentrated in Siping City, Changchun City, Liaoyuan City, Jilin City, northern Tonghua City and most of Baishan City. Areas with low cold wave risk are mainly concentrated in most of Baicheng City, most of Songyuan City and Yanbian Prefecture. Departments and other places are moderately risky areas of cold waves.

\section{Conclusions}

Based on GIS technology, this paper studies the risk zoning of cold wave disaster in Jilin province. Various index values were determined by analyzing the risk of cold wave and the vulnerability of the disaster-bearing body in Jilin Province. Finally, a weighted synthesis method was applied to obtain the risk distribution 
of cold wave disasters in Jilin Province, which provided a certain scientific basis for the cold-water disaster prevention in Jilin Province, to make up for the gap in this stage of the meteorological disaster risk assessment in Jilin Province. The following conclusions are gotten:

1) The average number of days of cold wave occurring in Jilin Province from 1961 to 2016 is 8.3 days. The months with the highest number of cold wave days were mainly concentrated in February, followed by December and January, and spring cold waves mostly occurred in March. With the global warming, the frequency of cold waves in Jilin Province has decreased after 1980, but it has increased in the past 10 years.

2) From the Cold Wave Disaster Risk Zoning Map in Jilin Province, due to factors such as topography and land use distribution, the west and east of Jilin Province have a certain resilience to the disasters caused by cold waves, and the risk of disasters is low. The distributions of agricultural facilities and large-area farmland in the central region are extremely sensitive to the cold wave disasters and have a high risk of disasters. Areas with high risk of cold wave are mainly concentrated in Siping City, Changchun City, Liaoyuan City, Jilin City, northern Tonghua City, and Baishan City. Areas with low cold wave risk are mainly concentrated in most of Baicheng City, most of Songyuan City, and Yanbian Prefecture. Other places are moderately risky areas of cold waves.

\section{Conflicts of Interest}

The authors declare no conflicts of interest regarding the publication of this paper.

\section{References}

[1] Zhang, J.Q. and Li, N. (2007) Quantitative Methods and Applications for Risk Assessment and Management of Major Meteorological Disasters. Beijing Normal University Press, Beijing.

[2] Lu, Y.L. and Xiao, G.J. (2001) Meteorological Disasters and Their Defenses. Weather Press, Beijing.

[3] Liang, D.P., Sun, Z.G., Guo, J., et al. (2016) Study on Meteorological Disaster Risk Zoning in Jinnan District of Tianjin Based on RS and GIS. Journal of Meteorology and Environment, 32, 116-121.

[4] Fang, X.Y., Du, W.P., Quan, W.J., et al. (2016) Research on Risk Zonation of High Temperature Disaster in Jiangsu, Zhejiang and Shanghai. Journal of Meteorology and Environment, 32, 109-115.

[5] Xu, Y.X. (2017) Risk Assessment and Regionalization of Flood Disaster in Shanxi Based on GIS. Disaster Science, 32, 103-108.

[6] Yang, L., Cao, C.R., Lin, Q., et al. (2015) Evaluation of Disaster Risk and Defensive Behavior of Typhoon "Su Li". Journal of Meteorology and Environment, 31, 106-111.

[7] Sun, R.Y. (2011) Analysis of Agricultural Meteorological Disaster Changes in Liaocheng City. Agricultural Disaster Research, 1, 73-74.

[8] Bao, J.W., Yu, Y. and Ye, R.Y. (2011) Effect of Low Temperature on Yield of Spring Wheat at Seedling Stage and Measures for High and Stable Yield. Ningxia Agricul- 
ture and Forestry Technology, 52, 56-57.

[9] Wang, L.J. and Li, T.L. (2011) Effect of Low Night Temperature Treatment on Sucrose Synthesis Ability of Tomato Leaves in Seedling Stage. Agriculture Science \&Technology, 12, 707-709.

[10] Zhang, G.C. (2010) Meteorological Disaster Risk Assessment and Zoning Method. Weather Press, Beijing.

[11] Liu, Y.Y., Shi, D.M., Hu, Y.X., et al. (2013) Risk Analysis and Regionalization of Agricultural Meteorological Drought Disaster in Jilin Province. Journal of Ecology, 32, 1518-1524.

[12] Wang, D.N., Guo, C.M., Liu, S., et al. (2013) Climate Risk Assessment and Regionalization of Delayed Rice Chilling Damage in Jilin Province. Journal of Meteorology and Environment, 29, 103-107.

[13] Shi, S.Q., Chen, Y.Q., Li, Z.G., et al. (2011) Spatialization of Factors Based on Spatial Interpolation Analysis and Maize Planting Division in Jilin Province. Geographical Science, 31, 408-414.

[14] Yuan, F.X., Li, Z.H., Wang, L.C. and Chen, L.M. (2011) Risk Prevention and Control Division of Main Crop Diseases and Pests in Jilin Province. Journal of Natural Disasters, 20, 64-72.

[15] Ma, S.Q., Wang, Q., Wang, C.Y., et al. (2008) Climatic and Economic Risk Zoning for Low Temperature Chilling Injury of Maize in Northeast China. Geographical Science, 27, 1169-1177.

[16] Yuan, F.X. and Ma, S.Q. (2004) Risk Assessment of Rice Production in Northeast China. Jilin Weather, 2, 32-34.

[17] Chen, K.Q. and Mi, N. (2016) Risk Assessment of Chilling Damage and Frost Disaster in Maize in Liaoning Province. Journal of Meteorology and Environment, 32, 89-94.

[18] Xi, Z.X., Wang, W.Y. and Shi, X.L. (2008) Spring Drought Risk Assessment and Zoning in Jilin Province. China Agricultural Meteorology, 29, 119-122.

[19] Shi, D.M. and Liu, Y.Y. (2012) Study on Evaluation of Regional Disaster Risk of Meteorological Disasters in Jilin Province. Jilin Weather, 1, 2-3.

[20] Ji, L.L., Xu, H., Xi, Z.X., et al. (2013) Climate Characteristics and Topographical Influence Analysis of Cold Wave Process in Jilin Province. Jilin Weather, 3, 21-23.

[21] Wang, Y.P., Li, J.S. and Liu, L.Y. (1999) The Application of Analytic Hierarchy Process in Determining the Weight Coefficient of Evaluation Factors. Journal of First Military Medical University, 19, 377-379.

[22] Saaty, T. (1980) The Analytical Hierarchy Process. Megraw-Hill, New York.

[23] Xin, Z.H., Xue, K. and Wang, J.X. (2013) Risk Stratification Method of Cold Tsunami Disaster in Dongying City. Agricultural Disaster Research, 3, 21-24.

[24] Zhang, J.Q. (2004) Risk Assessment of Drought Disaster in the Maize-Growing Region of Songliao Plain. Agriculture, Ecosystems \& Environment, 102, 133-153.

[25] Tang, W.A., Tian, H. and Yang, Y.J. (2012) Research on Risk Zonation of Cryogenic Freezing Disaster Based on GIS-A Case Study of Anhui Province. Geographical Science, 32, 356-361.

[26] Xie, J.F., Shi, D.M., Hu, Y.X., et al. (2013) Study on Regional Classification and Assessment of Storm Disaster Risk in Jilin Province Power Grid. Disaster Science, 28, 48-53.

[27] Zhejiang Deqing County People's Government Planning Group (2009) Deqing County Meteorological Disaster Defense Plan. Weather Press, Beijing. 